\title{
The Impact of COVID-19 on Developing Neurologic Disorders
}

Piotr Tekiela, MD, and Jennifer J. Majersik, MD, MS

Neurology ${ }^{\circledR}$ 2021;96:ee647-e649. doi:10.1212/WNL.0000000000011348

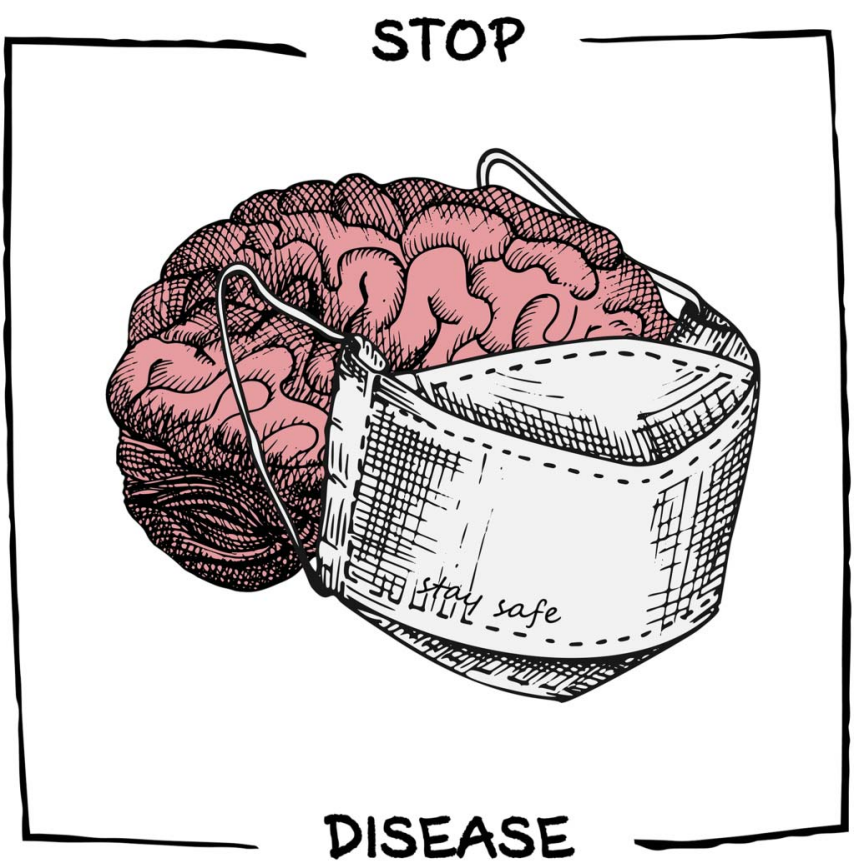

Related Article

\section{A Prospective Study of \\ Neurologic \\ Disorders in \\ Hospitalized \\ Patients With \\ COVID-19 in New \\ York City}

http://dx.doi.org/10.1212/

WNL.0000000000010979

\section{MORE ONLINE}

COVID-19 Resources

For the latest articles, invited commentaries, and blogs from physicians around the world

NPub.org/COVID19

One of the greatest challenges of treating a new virus is the lack of information about it. When little is known about a virus, patients affected by it, as well as their families, are left with uncertainty. In an article appearing in this issue of Neurology ${ }^{\circledR}$, Dr. Frontera and her team aimed to determine how often patients hospitalized with coronavirus disease 2019 (COVID19) developed new neurologic disorders. ${ }^{1}$ They then compared several key outcomes in treatment between patients who developed a new neurologic disorder due to COVID-19 and those who did not. These included discharges to home, ventilator use, length of hospital stay, and in-hospital deaths. These findings can help us understand which groups of people may be more likely to develop more severe disease after having COVID-19, as well as what their prognosis is likely to be.

\section{How Was the Study Done?}

The study was run during the first wave of the COVID-19 pandemic, from March 10 through May 20, 2020, in 4 hospitals in the New York City metropolitan area. The researchers set strict guidelines for the type of patients they would include in the study. Patients had to be adults with a laboratory-confirmed severe acute respiratory syndrome coronavirus (SARS-CoV-2) infection. They also had to have been admitted to the hospital at some point during the duration of their illness. Patients who were only seen in an emergency department or at an outpatient clinic were not included in the study.

There are 3 major strengths of this study that set it apart from other studies. First, patients were excluded if they were not tested for SARS-CoV-2 or if they tested negative 
for the virus. Second, all of the neurologic diagnoses made during the study were determined by a neurologist. Lastly, only new diagnoses of neurologic disease were included in the study. If someone had a neurologic disorder that was known before hospitalization due to COVID-19, that diagnosis was not counted in the study results. This improved the accuracy of diagnosing new neurologic complications that appeared to be caused by COVID-19.

\section{What Were the Results?}

A total of 4,491 patients were hospitalized with COVID-19 at the 4 hospitals involved in the study. Of those patients, 606 (13.5\%) developed a new neurologic disorder, as diagnosed by a neurologist. These disorders included a confused state in 51\% (called a toxic-metabolic encephalopathy), stroke in 14\%, seizures in 12\%, and brain injury due to lack of oxygen or blood flow (called hypoxic or ischemic disorders) in $11 \%$ (see below to learn more about these disorders). The researchers did not find any infections in the brain (such as meningitis or encephalitis) or in the spinal cord (myelitis) in these patients. The patients at highest risk of developing a neurologic disease were older and more likely to be male, White, or diabetic.

For most patients (54\%) who developed a neurologic disorder, the disorder appeared about 2 days after the initial COVID-19 symptoms (fever, cough, nausea, vomiting, or diarrhea) arose. In $43 \%$ of patients, neurologic problems developed at approximately the same time as their initial COVID-19 symptoms. Only $2 \%$ of patients developed neurologic symptoms before onset of the common COVID-19 symptoms.

Development of new neurologic disease was associated with worse outcomes overall. Patients who developed a neurologic disorder along with COVID-19 were 28\% less likely to be discharged home from the hospital and $38 \%$ more likely to die (either from the illness or from the neurologic disorder). Further, they spent 6 more days on a ventilator and 4 more days in the hospital than patients who did not develop a new neurologic disorder.

\section{Why Is This Important?}

The neurologic diseases found in the patients who were hospitalized with COVID-19 are frequently seen in patients with other critical care illnesses. These include acute respiratory distress syndrome, sepsis, low oxygen, low blood pressure, and acute kidney failure. It is reassuring that none of the 18 patients who had their CSF (the fluid found around the brain and spinal cord) tested had the SARS-CoV-2 virus detected in the fluid. This means the symptoms the patients experienced were not a result of the virus attacking the brain or spinal cord directly. Perhaps it is the critical illness itself causing the various neurologic diseases. It will likely be some time before that mystery is solved.

\section{What Remains Unknown?}

Because this study did not examine patients who had COVID-19 but were not hospitalized with it, it does not tell us how likely it is that patients with milder cases of COVID19 will develop a neurologic disorder as a result of the illness. It also does not tell us anything about the potential long-term neurologic effects that may arise from COVID-19. Lastly, our knowledge of and treatments for the virus have improved since the time of this study, and more people are surviving COVID-19 infections. We do not know if the complication rates would be different if they were measured today. 


\section{About Neurologic Complications in Critical Illness}

\section{Critical Illness and Encephalopathy}

Some patients who are hospitalized can become so sick that they require treatment in the intensive care unit. At that point, they are considered critically ill. There are many conditions that fall under this definition. However, these conditions typically share some common features, such as unstable blood pressure (too low or too high) and difficulty with breathing, with the patient requiring oxygen or a ventilator as a result. Critically ill patients are watched very closely and require specialized nursing care along with multiple specialists. These patients frequently have organs that either stop working normally or stop working altogether. The brain is one of these organs. When it begins to malfunction due to an underlying illness-for example, COVID-19patients can develop what is called toxic-metabolic encephalopathy. Signs of this include confusion, hallucinations, agitation, trouble sleeping, difficulty speaking, and many others. ${ }^{2}$ These symptoms are not necessarily due to permanent brain damage. Instead, they can be a sign that the body is very sick, and that the patient's organs are not working properly or have failed. Encephalopathy is associated with lower survival rates and increased risk of poor health outcomes after the patient is no longer in critical condition. As the underlying cause is treated, these symptoms typically start to improve, and eventually the person's brain function improves as well.

\section{Toxic-Metabolic Encephalopathy}

Toxic-metabolic encephalopathy is a medical term that describes someone who is confused as a result of being sick, such as from a bacterial, fungal, or viral infection (including COVID-19). Other causes include toxins, electrolyte imbalances, or hormone imbalances. It can also occur as a result of organ failure.

\section{Seizures}

Seizures can be experienced by critically ill patients. Seizures may be seen even in patients who did not have them before they were ill. Such seizures are described as "provoked seizures," because they happen as a result of an acute illness, rather than from underlying brain damage that makes someone susceptible to seizures. During critical illness, brain cells are not working properly and can misfire. This can trigger additional brain cells to misfire, causing large electrical storms in the brain, which we call seizures. These provoked seizures are treated the same way as other seizures, using the same medications. However, the expectation is that once the patient recovers from the critical illness, the seizures will stop as the brain begins to work properly again, and the patient eventually will not require seizure prevention medications (figure).

\section{Meningitis/Encephalitis}

Meningitis means inflammation of the meninges, which is the lining that surrounds the brain and spinal cord. Encephalitis is inflammation of the brain itself. It is possible to have inflammation of one structure without the other, so these terms are not interchangeable. These conditions are typically caused by an infection due to a virus, fungus, or bacteria. Rarely, chemicals and certain medications can also be the cause.

\section{Myelopathy}

This is an injury of the spinal cord, although this definition does not specify the reason for the injury.

\section{COVID-19 Prevention}

COVID-19 has proven to be very contagious, and it is now known to cause many medical and neurologic complications. The best way to avoid these complications remains avoiding COVID-19 infection altogether. Our knowledge of how COVID-19 spreads continues to evolve, which can make it difficult to keep up with the latest information. Because of this, we encourage all readers to stay up to date on the most recent evidence-based COVID-19 guidelines by visiting the Centers for Disease Control and Prevention website (cdc.gov/coronavirus/2019-ncov/index.html).

\section{For more information}

Brain \& Life

brainandlife.org

\section{American Brain Foundation}

americanbrainfoundation.org/

Centers for Disease Control and Prevention

cdc.gov/coronavirus/2019-ncov/index.html

\section{References}

1. Frontera JA, Sabadia S, Lalchan R, et al. A prospective study of neurologic disorders in hospitalized patients with COVID-19 in New York City. Neurology 2021;96:575-586.

2. Williams S. Pathophysiology of encephalopathy and delirium. J Clin Neurophysiol 2013;30:435-437. 


\title{
Neurology
}

\author{
The Impact of COVID-19 on Developing Neurologic Disorders \\ Piotr Tekiela and Jennifer J. Majersik \\ Neurology 2021;96;e647-e649 \\ DOI 10.1212/WNL.0000000000011348
}

This information is current as of January 25, 2021

\section{Updated Information \& Services}

\section{References}

Subspecialty Collections

Permissions \& Licensing

Reprints including high resolution figures, can be found at: http://n.neurology.org/content/96/4/e647.full

This article cites 2 articles, 0 of which you can access for free at: http://n.neurology.org/content/96/4/e647.full\#ref-list-1

This article, along with others on similar topics, appears in the following collection(s): COVID-19

http://n.neurology.org/cgi/collection/covid_19

Information about reproducing this article in parts (figures,tables) or in its entirety can be found online at:

http://www.neurology.org/about/about_the_journal\#permissions

Information about ordering reprints can be found online: http://n.neurology.org/subscribers/advertise

Neurology ${ }^{\circledR}$ is the official journal of the American Academy of Neurology. Published continuously since 1951, it is now a weekly with 48 issues per year. Copyright (O) 2021 American Academy of Neurology. All rights reserved. Print ISSN: 0028-3878. Online ISSN: 1526-632X.

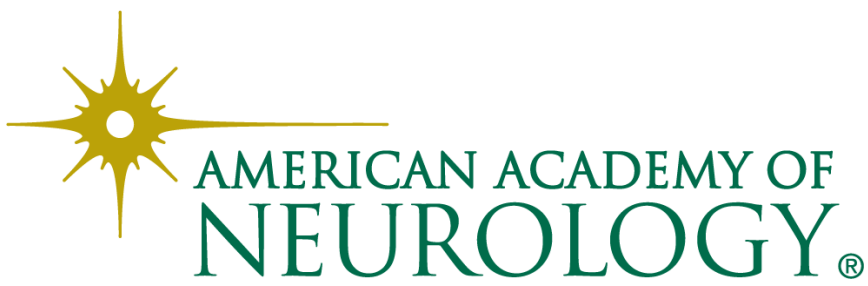

